\title{
Ends Xist, but where are the beginnings?
}

\author{
Davor Solter ${ }^{1}$ and Grace Wei \\ Max-Planck Institute of Immunobiology, 79108 Freiburg, Germany
}

What song the Syrens sang, or what name Achilles assumed when he hid himself among women, though puzzling questions, are not beyond all conjecture.

Sir Thomas Browne, Hydryotaphia, Ch. 5

The difference in the number of $\mathrm{X}$ chromosomes between homogametic and heterogametic individuals requires some kind of dosage compensation to ensure equal levels of $\mathrm{X}$-linked gene activity, regardless of whether one or two $\mathrm{X}$ chromosomes are present. Mechanisms for achieving dosage compensation vary significantly between different animals: In Drosophila, the single $\mathrm{X}$ chromosome in males is hypertranscribed with twice the efficiency of a female X chromosome; in Caenorhabditis elegans, the female $\mathrm{X}$ chromosomes are hypotranscribed (Kelley and Kuroda 1995). An alternative mechanism is found in marsupials and eutherian mammals, in which one X chromosome in XX female embryos is permanently inactivated in every cell soon after conception. It is of interest to note that in cases in which the sex chromosomes are very small, for example, in birds, dosage compensation has not been observed, as if the small number of genes that will be differentially expressed in males and females is not worth the effort to inactivate them.

$\mathrm{X}$ inactivation in mammals was first suggested by Mary Lyon (1961), and since the beginning, the process has presented numerous puzzles as to its exact mechanism and control, its variations between marsupials and eutherian mammals, its purpose, evolution, and functional significance. Our understanding of the precise molecular mechanism of X inactivation is still only partial, but the discovery of the human XIST gene, and its mouse equivalent, provided the first insight into the molecular control of $\mathrm{X}$ inactivation; the Xist gene is expressed only from an inactive $X$ and codes for untranslated RNA, whose expression seems both necessary and sufficient for X inactivation (for review, see Rastan 1994; Willard 1996). Expression or, more specifically, significant upregulation of Xist expression precedes complete $\mathrm{X}$ inactivation, although a precise temporal relationship has not been established. Timing of $\mathrm{X}$ inactivation following conception differs in various parts of the conceptus and,

${ }^{1}$ Corresponding author.

E-MAIL solter@immunbio.mpg.de; FAX 497615108569. in mouse, generally follows in step with the process of tissue differentiation. Namely, in the first differentiated tissues, trophectoderm and primitive endoderm, $\mathrm{X}$ inactivation occurs early, whereas in the tissues that form the embryo proper, $\mathrm{X}$ inactivation occurs a day or more later (Tan et al. 1993). An even later site of X inactivation is in the male germ line during spermatogenesis. Invariably, $\mathrm{X}$ inactivation in extraembryonic tissues involves only the paternal $\mathrm{X}$ (imprinted inactivation). In contrast, either the maternal or the paternal X can be inactivated in the cells forming the embryo proper (random inactivation). Thus, in eutherian mammals, two different mechanisms of $X$ inactivation could exist; regardless of the mechanism, the final result, in terms of dosage compensation, is identical (in marsupials one observes only imprinted $X$ inactivation). A possible third mechanism leading to $\mathrm{X}$ inactivation may operate during spermatogenesis, as spermatocytes are the only cells believed to inactivate the single $\mathrm{X}$ in males.

Penny et al. (1996) demonstrated the indispensability of Xist expression for $\mathrm{X}$ inactivation by analyzing an XX mouse embryonic stem (ES) cell line in which several kilobases were removed from the first exon of one Xist allele by gene targeting. Upon differentiation in vitro and in vivo (in chimeric embryos), they invariably observed nonrandom $\mathrm{X}$ inactivation affecting the $\mathrm{X}$ chromosome with the intact Xist. Although this study demonstrated that an X chromosome lacking Xist is not inactivated, it did not address the role of $X$ inactivation in development. Initial analysis of this important problem is presented in the paper by Marahrens et al. (this issue). Their most important results can be summarized as follows: (1) Males with $\mathrm{X}^{\text {Xist }}{ }^{-}$chromosome are normal and fertile; (2) female embryos that inherit $\mathrm{X}^{X i s t^{-}}$chromosome from the father fail to develop and die soon after implantation; and (3) females that inherited $\mathrm{X}^{\mathrm{Xist}^{-}}$chromosome from their mother are normal, fertile, and the paternal $\mathrm{X}$ chromosome is inactivated in all their cells. What do these results mean with respect to understanding different $\mathrm{X}$ inactivation mechanisms mentioned above? 


\section{$\mathbf{X}$ inactivation and spermatogenesis}

Numerous lines of evidence suggest that the $\mathrm{X}$ chromosome is transcriptionally inactivated at the beginning of male meiosis, and the finding of Xist expression in spermatocytes, the only male cells to express Xist, seems to indicate that $\mathrm{X}$ inactivation is the responsible mechanism (McCarrey et al. 1992; Richler et al. 1992). Because $X_{\text {ist }}{ }^{-}$males are fertile, $\mathrm{X}$ inactivation is not essential for normal spermatogenesis, it occurs by an Xist-independent mechanism, or the observed reduced transcription of most X-linked genes during spermatogenesis and concomitantly low level of Xist expression have been misinterpreted as diagnostic of $\mathrm{X}$ inactivation. Xist ${ }^{-}$males produced by Marahrens and colleagues will be, one presumes, used to address these alternatives.

\section{Imprinted $X$ inactivation}

The finding that $\mathrm{X}_{\mathrm{M}} \mathrm{X}_{\mathrm{P}}{ }^{{ }^{X i s t}{ }^{-}}$embryos fail to develop is an important indication that the mechanisms regulating $X$ inactivation in extraembryonic and embryonic tissues are substantially different. The simplest explanation for the results described by Marahrens and colleagues is that there exists, for extraembryonic tissues, a regulatory mechanism that in essence commands, "Inactivate the paternal X without further proofreading." Such a mechanism obviously would suffice to handle $\mathrm{X}$ inactivation in normal embryos but fails to explain all the available experimental data. The sole existence of this mechanism without further elaboration would predict that all androgenetic embryos would fail as a result of not having any active $\mathrm{X}$ in extraembryonic tissues and that all parthenogenetic and gynogenetic embryos would fail as a result of having always two active $\mathrm{X}$ chromosomes, a condition that is lethal according to this report. A similar scenario was proposed by Latham (1996), although he suggested the existence of a counting mechanism and only a strong preference but not an absolute requirement for paternal $\mathrm{X}$ inactivation in extraembryonic tissues. The results of Marahrens et al. would indicate either the absence of a counting mechanism or the absolute inability to inactivate maternal $\mathrm{X}$ in extraembryonic membranes.

Is the counting mechanism really absent? Most likely not, as this would preclude the development of XO females that, at least in mice, are more or less normal, albeit with somewhat reduced fertility. The suggestion that $\mathrm{X}_{\mathrm{P}} \mathrm{O}$ embryos do not develop (Hunt 1991) has not been substantiated (Thornhill and Burgoyne 1993), and the observation may have been a result of the specific uterine environment. Overall, it seems that $\mathrm{X}_{\mathrm{P}} \mathrm{O}$ embryos develop normally or almost normally (Omoe and Endo 1993), which indicates that inactivation of the paternal $\mathrm{X}$ in extraembryonic membranes is not absolute.

Can the maternal $\mathrm{X}$ be inactivated in extraembryonic tissues? The report by Marahrens and colleagues suggests that it cannot, even under extreme selective pressure. This supports previous findings by Tada et al. (1993), who reported severe developmental abnormalities associated with $\mathrm{X}_{\mathrm{M}} \mathrm{X}_{\mathrm{M}} \mathrm{X}_{\mathrm{P}}$ and $\mathrm{X}_{\mathrm{M}} \mathrm{X}_{\mathrm{M}} \mathrm{Y}$ chromosomal complements. They observed growth retardation and deficient extraembryonic structures, phenotypes that are quite similar to those of parthenogenetic and gynogenetic embryos and certainly comparable to the phenotypes observed by Marahrens and colleagues in $\mathrm{X}_{\mathrm{M}} \mathrm{X}_{\mathrm{P}}{ }^{\text {Xist }^{-}}$ embryos. Thus, it would appear that the $\mathrm{X}$-inactivation mechanism in extraembryonic membranes operates along the lines of, "Count the number of X chromosomes; if there is more than one, inactivate the paternal $\mathrm{X}$, and if this is not possible, forget it." It is entirely likely that problems caused by the inability to inactivate the maternal $\mathrm{X}$ in extraembryonic membranes are restricted to the mouse, as the relatively normal development of individuals with Klinefelter's syndrome (XXY) or XXX women, both possessing supernumerary maternal X chromosomes, would indicate. One could speculate that because of the need for very early $\mathrm{X}$ inactivation in mouse extraembryonic tissues, the mechanism that could inactivate the maternal $\mathrm{X}$ is not yet operational or that complete $\mathrm{X}$ inactivation in human extraembryonic tissues is not essential (Migeon et al. 1985). These speculations obviously lead to the question not only of what is the nature of the signal for $\mathrm{X}$ inactivation, but also what regulates the differential timing of the signal in different parts of the conceptus. Furthermore, it is possible that the effects on placental growth and bizarre sex ratio distortions observed in various interspecific crosses in mice and ascribed to X-linked genes (Boyd 1996; Zechner et al. 1996) all reflect irregularities in the timing or extent of imprinted $\mathrm{X}$ inactivation caused by autosomes/X chromosome incompatibilities.

\section{Random $\mathrm{X}$ inactivation}

Although the results by Marahrens and colleagues concerning $\mathrm{X}$ inactivation in somatic tissues are rather predictable, the mice they generated will be very useful in addressing several puzzling aspects of $\mathrm{X}$ inactivation. Females that are $\mathrm{X}_{\mathrm{M}}{ }^{{ }^{X i s t}{ }^{-}} \mathrm{X}_{\mathrm{P}}$ are viable, with $\mathrm{X}_{\mathrm{P}}$ inactivated in all somatic cells as expected. This inactivation can occur in one of two ways (Penny et al. 1996). Primary nonrandom $\mathrm{X}$ inactivation implies that the $\mathrm{Xist}^{-} \mathrm{X}$ chromosome is recognized by the inactivation mechanism and ignored (either by not attempting to up-regulate Xist expression or by using Xist blocking factors on the normal X chromosome only). Secondary nonrandom $X$ inactivation (a more likely possibility) suggests that upregulation or blocking will occur at random but the nonfunctional allele of Xist, if chosen, would fail to inactivate its $\mathrm{X}$ chromosome in cis, thus resulting in two active $\mathrm{X}$ chromosomes. Cells with two active $\mathrm{X}$ chromosomes will be selected against or die (by apoptosis?). Is a similar (but smaller scale) cell elimination going on in normal XX embryos when failure or inaccuracy of the $\mathrm{X}$-inactivation mechanism leaves cells with either two or no active $\mathrm{X}$ chromosomes? Analysis of $\mathrm{X}^{\mathrm{Xist}} / \mathrm{X}$ embryos throughout development should answer the dilemma of primary versus secondary nonrandom $\mathrm{X}$ inactivation. In addition, using a tetraploid rescue approach, one should be able to produce $\mathrm{X}^{\text {Xist }} / \mathrm{X}^{\text {Xist }}{ }^{-}$embryos (and 
perhaps mice?) and determine whether Xist truly is indispensable for random $X$ inactivation in otherwise normal diploid somatic cells.

These and many other obvious questions /especially those related to the evolution of mammalian $\mathrm{X}$ inactivation) can be addressed using this important and interesting model. After reading the paper by Marahrens and colleagues, it becomes even more obvious that despite the tremendous progress made in the field over the last few years, the problem of $\mathrm{X}$ inactivation in mammals remains as complex and tantalizing as ever.

\section{References}

Boyd, Y. 1996. Non-mendelian inheritance of X chromosome markers in interspecific backcrosses. Nature Genet. 13: 393394.

Hunt, P.A 1991. Survival of XO mouse fetuses: Effect of parental origin of the X chromosome or uterine environment? Development 111: 1137-1141.

Kelley, R.L. and M.I. Kuroda. 1995. Equality for X chromosomes. Science 270: 1607-1610.

Latham, K.E. 1996. X chromosome imprinting and inactivation in the early mammalian embryo. Trends Genet. 12: 134138.

Lyon, M.F. 1961. Gene action in the X-chromosome of the mouse (Mus musculus L). Nature 190: 372-373.

Marahrens, Y., B. Panning, J. Dausman, W. Strass, and R. Jaenisch. 1997. Xist-deficient mice are defective in dosage compensation but not spermatogenesis. Genes \& $\mathrm{Dev}$. (this issuel.

McCarrey, J.R., D.D. Dilworth, and R.M. Sharp. 1992. Semiquantitative analysis of $\mathrm{X}$-linked gene expression during spermatogenesis in the mouse: Ethidium-bromide staining of RT-PCR products. Genet. Anal. Techniques Applic. 9: $117-123$

Migeon, B.R., S.F. Wolf, J. Axelman, D.C. Kaslow, and M. Schmidt. 1985. Incomplete X chromosome dosage compensation in chorionic villi of human placenta. Proc. Natl. Acad. Sci. 82: 3390-3394.

Omoe, K. and A. Endo. 1993. Growth and development of $39 \mathrm{X}$ mouse embryos at mid-gestation. Cytogenet. Cell Genet. 63: $50-53$.

Penny, G.G., G.F. Kay, S.A. Sheardown, S. Rastan, and N. Brockdorff. 1996. Requirement for Xist in X chromosome inactivation. Nature 379: 131-137.

Rastan, S. 1994. X chromosome inactivation and the Xist gene. Curr. Opin. Genet Dev. 4: 292-297.

Richler, C., H. Soreq, and J. Wahrman. 1992. X inactivation in mammalian testis is correlated with inctive X-specific transcription. Nature Genet. 2: 192-195.

Tada, T., N. Takagi, and I.-D. Adler. 1993. Parental imprinting on the mouse X chromosome: Effects on the early development of XO, XXY and XXX embryos. Genet. Res. 62:9 139148.

Tan, S.S., E.A. Williams, an P.P.L. Tam. 1993. X-chromosome inactivation occurs at different times in different tissues of the post-implantation mouse embryo. Nature Genet. 3: 170174.

Thornhill, A.R. and P.S Burgoyne. 1993. A paternally imprinted $\mathrm{X}$ chromosome retards the development of the early mouse embryo. Development 118: 171-174.

Willard, H.F. 1996. X chromosome inactivation, XIST, and pursuit of the X-inactivation center. Cell 86: 5-7.
Zechner, U., M. Reule, A. Orth, F. Bonhomme, B. Strack., J.-L. Guénet, H. Hameister, and R. Fundele. 1996. An X-chromosome linked locus contributes to abnormal placental development in mouse interspecific hybrids. Nature Genet. 12: $398-403$. 


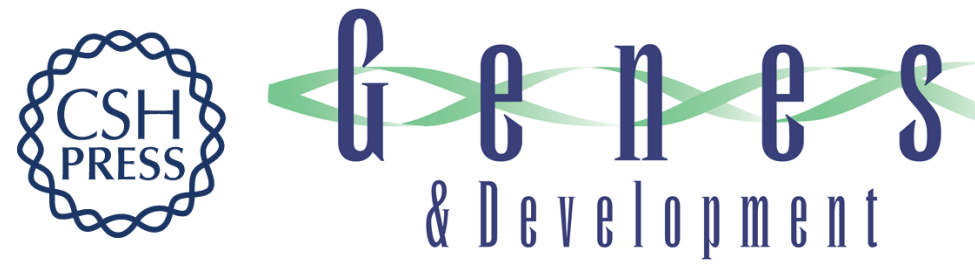

\section{Ends Xist, but where are the beginnings?}

D Solter and G Wei

Genes Dev. 1997, 11:

Access the most recent version at doi:10.1101/gad.11.2.153

References This article cites 16 articles, 4 of which can be accessed free at: http://genesdev.cshlp.org/content/11/2/153.full.html\#ref-list-1

License

Email Alerting

Receive free email alerts when new articles cite this article - sign up in the box at the top Service right corner of the article or click here.

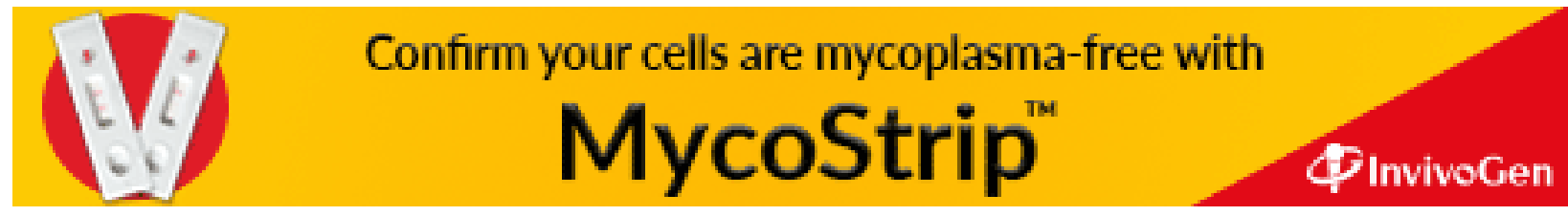

